\title{
Using business intelligence solutions for forecasting in marketing researches
}

\author{
Christina Albert Rayed Assad \\ Computer and Information System Department, Sadat Academy for Management Science, Egypt
}

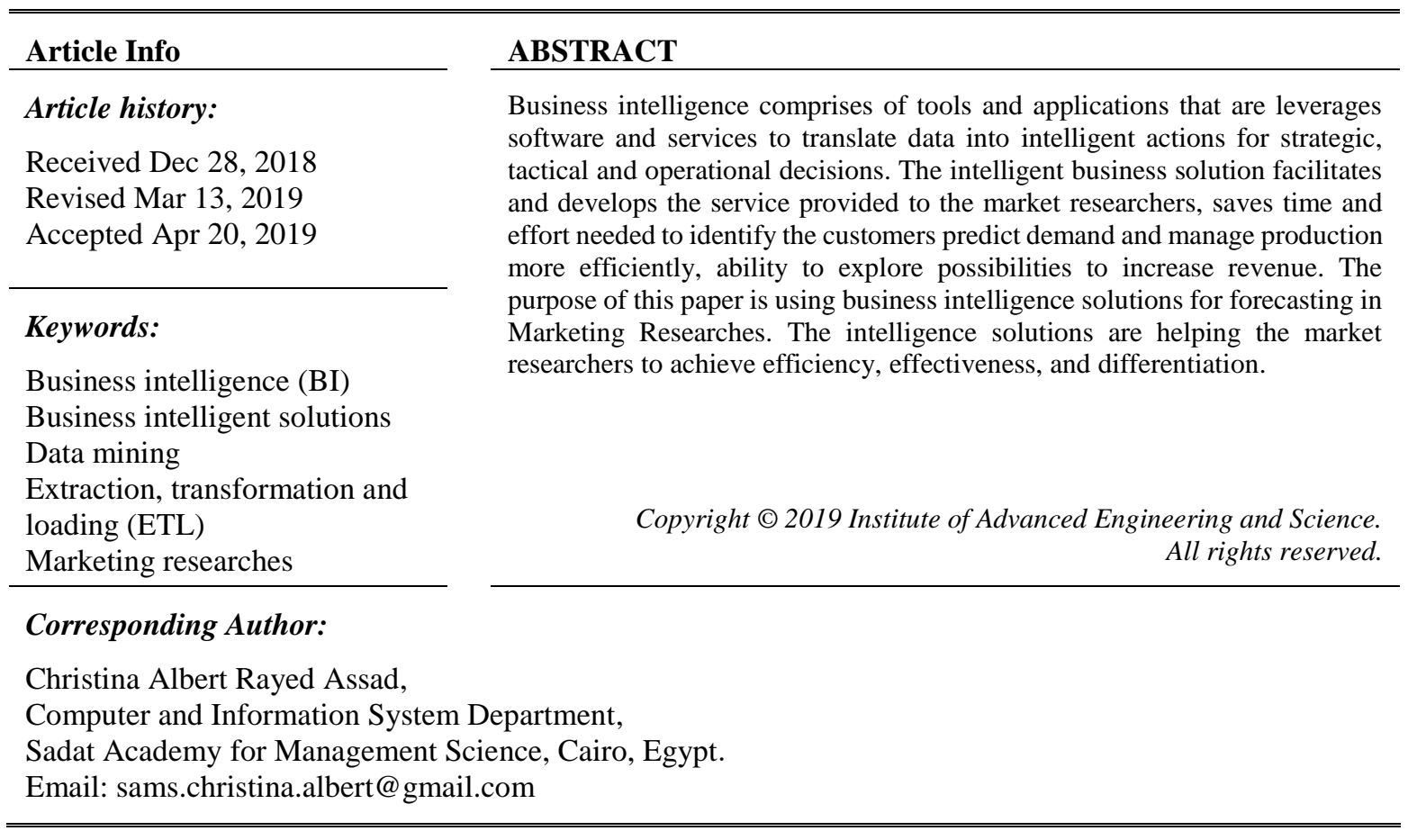

\section{INTRODUCTION}

Business intelligence is a powerful new management approach that-when done right-can deliver knowledge, efficiency, better decisions, and profit to almost any organization that uses it [1]. Business intelligence may be defined as a set of mathematical models and analysis methodologies that exploit the available data to generate information and knowledge useful for complex decision-making processes [2]. Business intelligence is depending on collecting data from various sources, by compressing these data can be analyzed from multiple aspects in order to support making marketing researches.Business intelligence is a broad category of applications and technologies for gathering, storing, analyzing, and providing access to data to help enterprise users make better business decisions. BI applications include the activities of decision support systems, query and reporting, online analytical processing (OLAP), statistical analysis, forecasting, and Data Mining [3].

Forecasting is a process of predicting or estimating the future based on past and present data. Forecasting process provides information about the potential future events and their consequences for the organization. Forecasting in market researches is very important for companies. It helps to enhance performance of companies and enhance customer relationships and provide strategic advantages. Several forecasting models existing each organization can choose the model which I suitable for its activities.

There are many problems in the global marketing related to the forcasting. In the globalization era, many companies face many challenges to pertrate and compitete in the global marketing. There are two important milesones in the marketing process: first is reducing costs and the second is increasing sales and revenue. Many companies face many challenges like acquization customers, repeated purchases, increasing customers, opening new markets and targeting the right customers in the right time. There are many marketing researches to investigate these problems and forcaste for solutions for these problems though the globalization market. 
So, the propsed intelligent business analytics solutions can assist for forcasting for the future and predicating of solutions for many marketing problems. Intelligent business analytics solutions develop all activities including collect, analyze and plan for new campaigns to gain a competitive advantage. Business Intelligence analytical solutions can help in sophisticated problems with large amount of data to reach to customized solutions in the right time. Therefore by using business intelligence analytical solutions for forecasting process will predict customized intelligent solutions.that will assist market researchers to increase sales and reduce costs in order to gain the pick revenue and enhance the organization image.

There are many previous researches that refer to the using of business intelligence solutions for supporting and predicting for decision making in the marketing researches. Business Intelligence possesses the capabilities that support superior business decision-making through past, present and predictive composition/trends of organization operations. Business intelligence is not a product, technology and or methodology, but a combination of all to leverage information assets within key business processes to achieve improved business performance [1]

Decision-making is everyday life activity and it is the essence of management [4]. Business Intelligence, the basic technology of Business Intelligence, and the contents of Supply Chain Integration and focuses on the analysis of the application of Business Intelligence in Supply Chain Integration to provide basis for enterprises to implement Business Intelligence [5].

\section{THE BUSINESS INTELLIGENCE ENVIRONMENT}

Business intelligence and analytics requires a huge amount of structured and unstructured data from different resources, analytic tools, and people who deal with these tools to plan and predict for the future and solve complicated problems. Specific case of business intelligence (BI) infrastructures, should be decided according to the speed of the decision-making processes, which are usually executed in real time. It is determine the flexibility rate at which the business can grow. Businesses grow but the key drivers can remain the same. It analyzes the elements required for an optimal deployment of smart decision architectures [6].

As shown in Figure 1 which gives an overview of a business intelligence environment starting with the data and ending with different solutions to the end users. The business intelligence environment consists of six milestones.

\subsection{Data}

In the business environment, there are different types of structured, semi structured and unstructured data from different resources with containing the mobile devices and social networks. All these data is needed by the decision makers in order to analyze to gain a competitive advantage.

\subsection{Business intelligent infrastructure}

Business intelligent infrastructure consists of the databases, data warehouse and data marts in order to turn data into information and information into knowledge and knowledge into strategic plans that gain a competitive advantage.

\subsection{Business analytics tools}

There are many business analytics tools like OLAP, data mining, statistical models, and reports.

\subsection{Management methods}

The management methods used to predict and forecast using key indicators of performance. Managers use a variety of managerial methods in order to demonstrate strategic business goals and performance management.

\subsection{Delivery platform}

The delivery platform contains management information system (MIS), decision support system (DSS), executive support system (ESS). The results from business intelligence and analytics are delivered to managers and employees in a variety of ways. MIS, DSS, and ESS that help track and keep information flowing in the amount and direction organization needs to stay on track, deliver information and knowledge to different levels of management from top, middle and low management. Delivery platform can present, summarize, and analyze data from an organization's databases or data warehouse to operational employees, middle managers, and senior executives. 


\subsection{User interface}

Today's business analytics software can deliver reports and summarized data through the using of smart phones and handheld computers. The user interface can be through web portals or mobile applications or social networks. Business analytics software highlights visual techniques such as dashboards and scorecards. Mobile business intelligence tool (MBIT) aims to provide these features in a flexible and cost-efficient manner. Business analytics software describes the detailed architecture of MBIT to overcome the limitations of existing mobile business intelligence tools. Business analytics software discusses the benefits of using service oriented architecture to design flexible and platform independent mobile business applications [7].

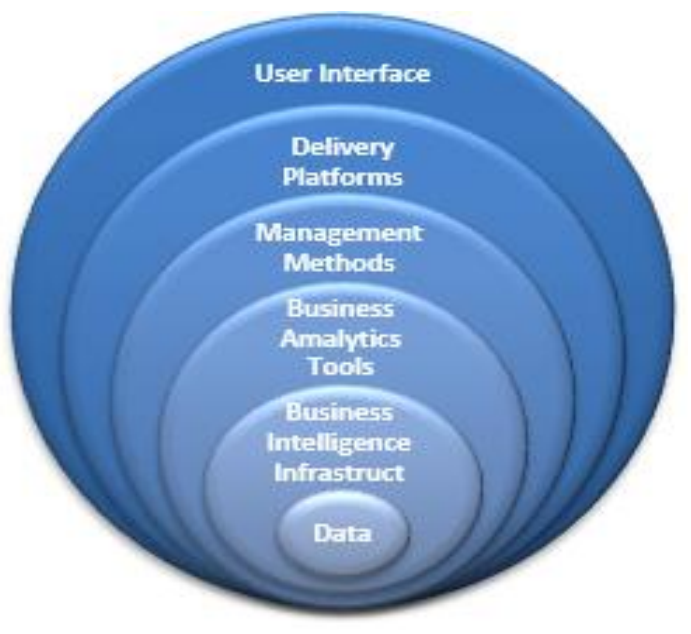

Figure 1. Business intelligence environment

\section{BUSINESS INTELLIGENCE SOLUTION ARCHITECTURE}

Business intelligence solution architecture is a collection of organizing the data, information management and technology components that are used to build business intelligence systems for generating reports and analyzing data. This architecture contains operational, strategic, tactical decision support applications and databases that provides the business community easy access to data in a real time special for market researches. Business intelligence solution architecture is based on the vision, mission and objectives of the business.

Business intelligence solution architecture consists of five stages as shown in Figure 2:

- Data modeling is one of the core phases of designing a BI solution and in this phase all the data that is gathered regarding requirements are used which means the data model will effectively function as a foundation for building the BI solution [8]. Source systems are essentially systems that provide a BI system with data thus the definition data sources. SAP (Systems Applications Products) has a different classification, and as such it associates data sources with metadata of source system, which is used when the actual data is transferred in the form of Info Packages. SAP defines four types of data sources for SAP source systems and these are grouped into two, based on the type of data, transaction data and master data [9].

- Data acquisition implies the extraction of data from source systems. An Extraction, Transformation and Loading (ETL) process can also be used to facilitate the data acquisition process

- Data extraction is an area where the data that is extracted from a source system is stored temporarily and in a raw format, that is without any changes to the data. SAP defines this area a Persistent Staging Area (PSA) [10].

- Data transformation phase, Transformation in this case implies that the source data is consolidated and formatted so that it can be transferred for further processing and analyzing. Once the data is in the staging area, it can be cleansed, transformed, and transferred to a cube. The process Extraction, Transformation and Loading (ETL) can support facilitating this stage. The ETL (Extract, Load, and Transform) is one of the main components of a business intelligence system that depends on data accuracy in order todata extraction.

- The data presentation layer of a BI solution ultimately represents the end user environment, where reports and queries are used to present the data in a certain format so that drill down analysis on multidimensional data can be performed [11]. The presentation layer may use modern web technologies such as Adobe flash, HTML5 and PDF to present easy to use, highly interactive, and user-friendly reports. 


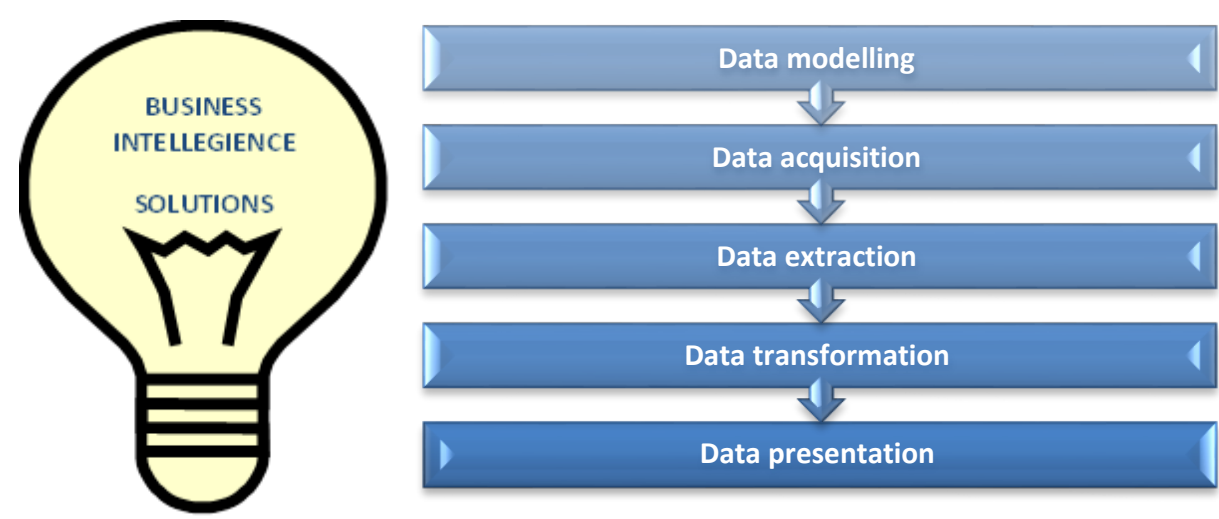

Figure 2. Business Intelligence solution Architecture

Even-Driven Architecture (EDA) based Right-Time Business Intelligence System Framework (EDA based RTBISF), which combines RT-BI and the business process based on the EDA and Agent, to resolve the environment uncertainty, business dynamics and to meet the needs of dynamic adjustment of business solution for the enterprise in the fierce competitive environment [12]. Specific case of business intelligence (BI) infrastructures, should be decided according to the speed of the decision-making processes, which are usually executed in real time. It is determine the flexibility rate at which the business can grow. Businesses grow but the key drivers can remain the same. It analyzes the elements required for an optimal deployment of smart decision architectures [6]. There are many essential factors in business intelligence solution architecture depending on scalability and high performance, agility, complete functionality, extensibility, rapid development and deployment.

\section{USING BUSINESS INTELLIGENCE SOLUTIONS IN MARKET RESEARCHES}

It's very important in the competitive business environment to offer new business intelligence solutions to increase the revenue and reduce expenses. The business intelligence solutions can offer a fast access to information at low cost in marketing researches that can lead to gain a competitive advantage and acquisition new customers and open new markets. Business intelligence solutions also offer intelligent queries and reports, so that they help in decision making.

One of the keys of business strategy for creating competitive advantages is understands the data that firms generate in its own business. Information processing has gradually become the basis for achieving competitive advantage. The organization has to believe that have the right information at the right time and available to the right people [13].

BI bridges between different systems and users wishing to access information, providing an environment that facilitates access to information needed for day to day activities, allowing analyze the business performance [14]. With BI organizations can integrate powerful tools, analysis, standardized reporting, monitoring system withvarious metrics, data integration, among other features within a serviceoriented architecture $[15,16]$.

E-business intelligence aims to develop a tremendous spectrum of business opportunities and user's adoption of the business intelligence is very important and relevant propositions are made [17]. Market intelligence (MI) is a process geared towards the market environment that an organisation operates in and differentiates itself from market research with the analytic capabilities [18].Market intelligence is decisioncentric and expressed by some marketing researches, Market intelligence is a subset of business intelligence to gain from the experiences and to anticipate the future market opportunities before the competition.

Customer Relationship Management (CRM) systems and Business Intelligence provides a holistic approach to customers which includes improvements in customer profiling, simpler detection value for customers, measuring the success of the company in satisfying its customers, and create a comprehensive customer relationship management [19]. Business Intelligence and Business Process Management (BPM) applications is using for data analysis and simulation of forecasting in market researches.

Using business intelligence applications includes three stages as shown in Figure 3; the first stage is analysis that contains the using of data mining, advanced analysis, Visual and OLAP analysis. The second phase is reporting by creating marketing and statistical reports. The last phase is monitoring which contains dashboards, scorecards and mobile apps. 


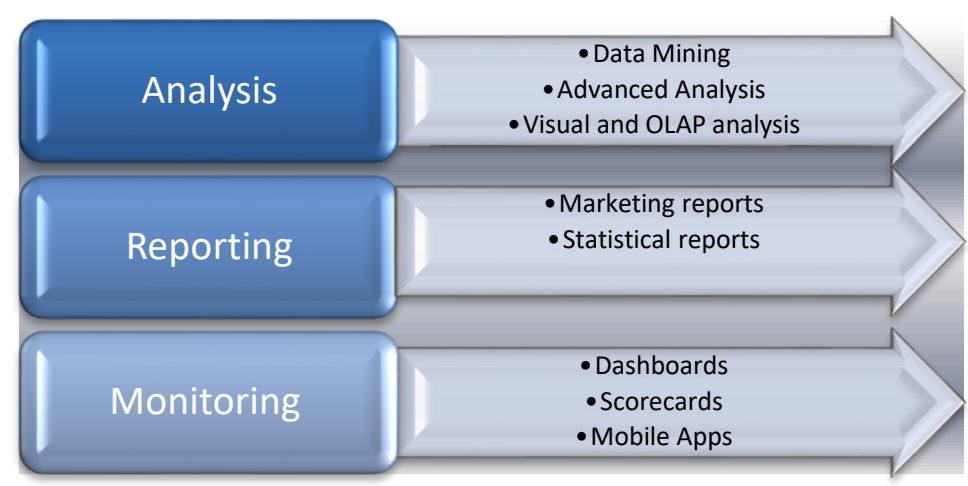

Figure 3. Stages of using business intelligence solutions

By applying these three stages in market researches, the business intelligence solution must aim to ensure the business strategy, increase the economics scales, offer the full range of business intelligence functionality, generate integration reports to dashboards ,OLAP, ad hoc queries and mobile applications, accessibility and real time access, agility to Rapid Development and Deployment and Consistency and security issues.

\section{APPLYING BUSINESS INTELLIGENVE SOLUTIONS IN MARKETING RESEARCHES}

By applying business intelligent solutions in market researches, will achieve the reported that the major goals for the companies such as increase revenue, reduce costs, and increase productivity.This paper presents a business intelligence solution framework for applying business intelligence solution in market researches. The proposed framework is structured in four phases as shown in Figure 4; planning, analyzing, execution and dissemination.

\subsection{Planning stage}

In this stage, it's important to obtain the approvals from the management, illustrate the objectives and goals, put the methodology for applying and create the plan. The planning study includes the data modeling and acquisition. After determining the market, business intelligence solutions starts to collecting internal and external data which containing all types of data structured, semi-structured and unstructured data in order to data modeling and acquisition.

\subsection{Analyzing stage}

There are many analytical methods must be applied in order to get value out such as OLAPs, planning and forecasting methods, statistical models optimization and simulation. In the analysis stage, there are different types of analysis as following; strategic, tactical and operational analysis. Each type of analysis support the different levels of management; top, middle and operational.

\subsection{Execution stage}

In the execution stage, there is a need to increase revenue and reduce cost. The business intelligence solution's role is to take the right decisions in the right time to maximize the benefits of using business intelligence solution in market researches and fast access to profiles of customers in order to present right services at the right time. Many reports can execute like operational, web, and exception reports.

In this stage, the business intelligence solution can help all levels of management. At a strategic level, the business intelligence solution can help the top managers to put the strategies and objective, generate smart reports, forecast for the future, make optimization and simulation. At a tactic level, the business intelligence solution can help the middle managers for taking decisions o different fields such as inventory, sales, marketing, finance and so on. Finally at the operational level, business intelligence solutions can be useful for querying and day to day operations reports.

\subsection{Dissemination stage}

In the dissemination stage, there are many applications containing mobile apps and Alerts, dashboards and scorecards, OLAP analysis, data mining, run time reporting, decision engines and advanced analysis. 


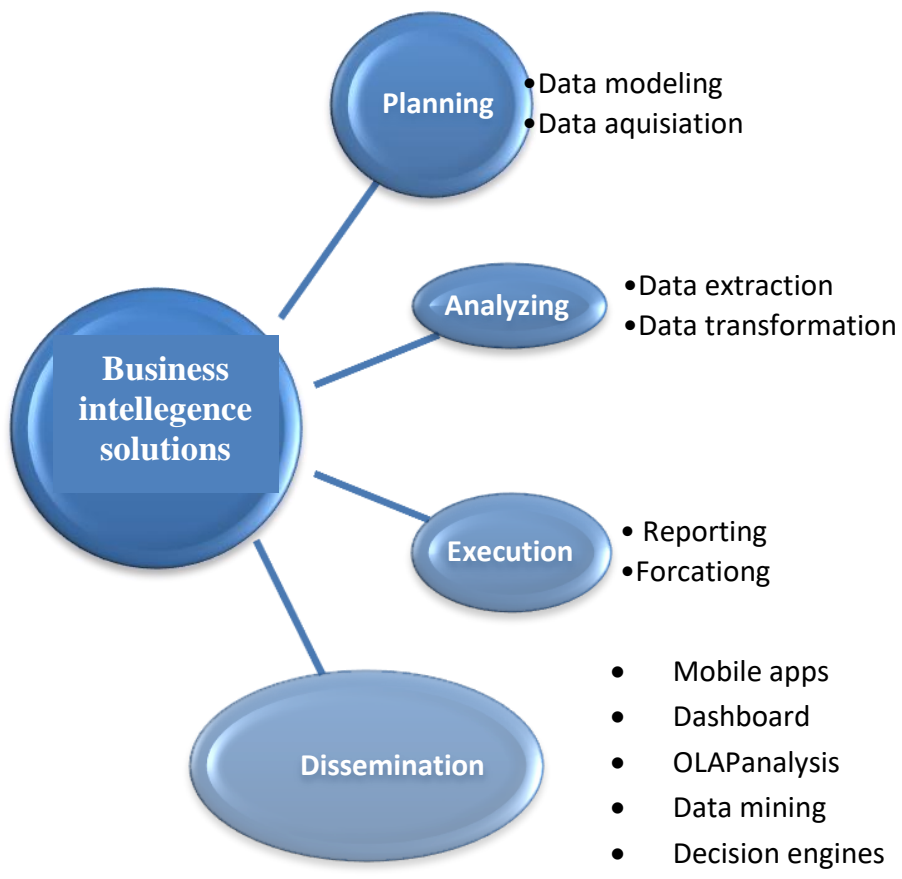

Figure 4. Business Intelligence solution framework

\section{BENEFITS OF USING BUSINESS INTELLIGENCE SOLUTIONS IN MARKETING RESEARCHES}

BI helps administrators by breaking down information from various resources in better basic leadership at both tactical and strategic level, for customary utilization, conventional data frameworks farewell, yet for hierarchical and functional planning; new tools are required for business analysis [20].

Business analytics programs stress the utilization of quantitative analyses, predictive models and statistical tools to help organizational leadership gain a different view of their data, derive maximum value from its interpretation, and utilize the results to improve decision making and problem solving [21].

There are many benefits of using business intelligence solutions in marketing researches as:

- $\quad$ Analyze different types of data from different sources,

- Take intelligent decisions on the different levels of managements,

- Improve accuracy in predictions in different fields,

- $\quad$ Achieve operational efficiency,

- Make fundamental changes serving as finding new collaborations, acquiring new customers, opening new markets,

- $\quad$ Add value in the supply chain for the products or services to the customers,

- Enhance the administrative process efficiencies.

- $\quad$ Ensure the business strategy,

- Increase the economics scales,

- Offer the full range of business intelligence functionality,

- Generate integration reports to dashboards ,OLAP, ad hoc queries and mobile applications,

- Increase accessibility and real time access,

- $\quad$ Agile to Rapid Development and Deployment.

\section{RESULTS AND DISCUSSION}

According to the previous studies, there are different approaches for applying business intelligence solutions. The using of business intelligent solutions differs from one company to the other depending on the size and the budget of the company. As Robert Walters said BI managers are increasingly utilising BI for performance management (12\%) and predictive analysis (13\%) to promote business growth [22]. The percentages of using business intelligence tools can be viewed in Figure 5. 


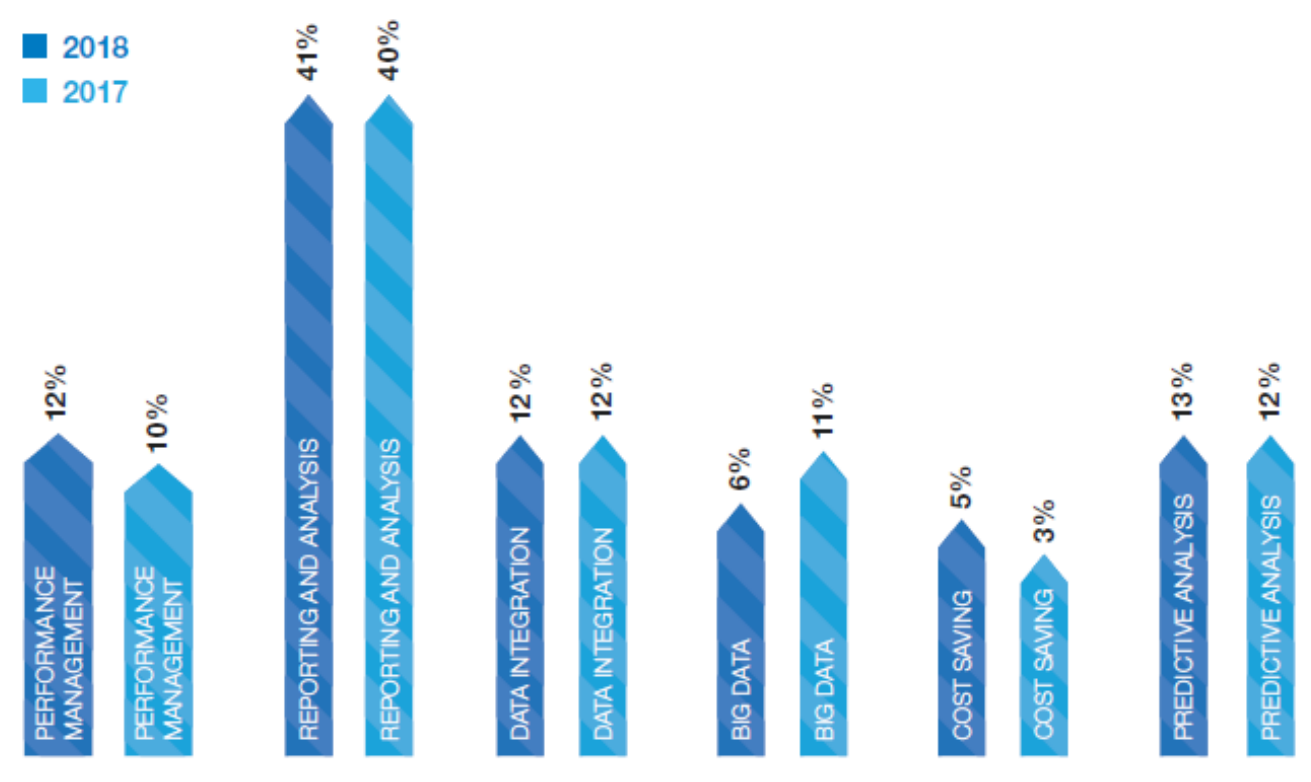

Figure 5. The percentages of using business intelligence tools [20]

In this paper, by applying business intelligence solutions framework on some companies worldwide as a pilot study which presenting services like electronic banking, telecommunications, healthcare servies, electronic banking and electronic learning. The companies will need to employ cost-effective business intelligence (BI) solutions.In the business intelligence solutions framework there are some phases that will apply in many companies like planning and analzing. These two phases are used by many companies in order to forecasting and predicting for the future. According to the four phases in the business intelligence solutions framework, the applying perentage of using business intelligence in planning is $79.75 \%$, the second phase (analyzing phase) percentage is $53.75 \%$, the third phase (exectution phase) percentage is $41 \%$ and the last phase ( dissemination phase) percentage is $32.25 \%$ as shown in Figure 6.

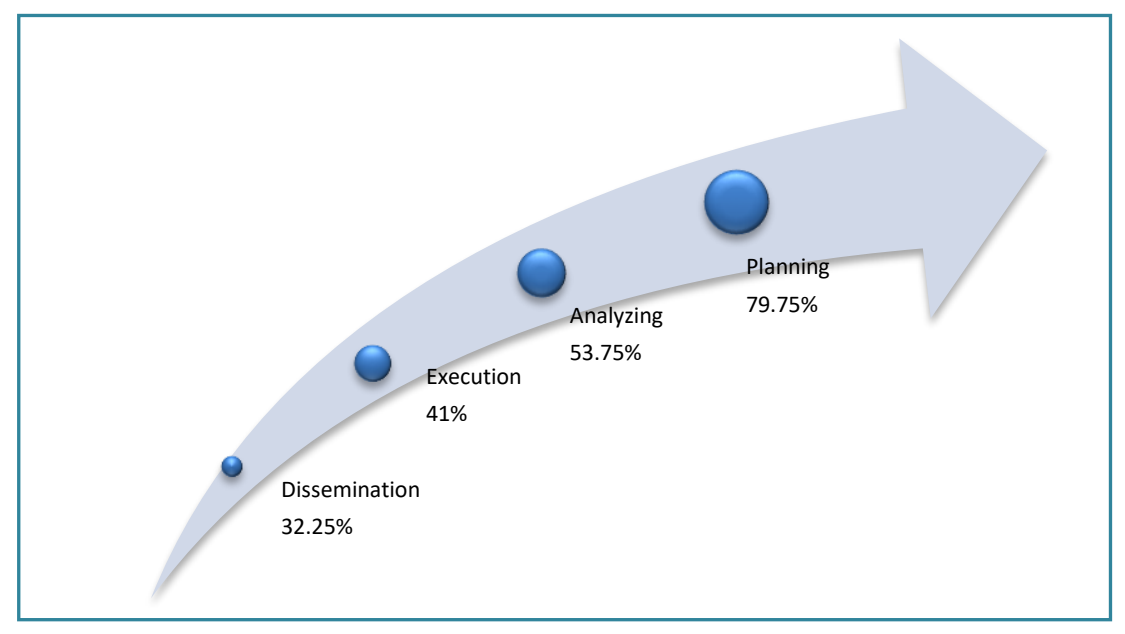

Figure 6. The percentages of the framework's phases

According to the pilot study, the greatest companies that applying business intelligence solutions is telecommunication then electronic banking. The latest companie is electronic learning. Farthermore the panning and analyzing phases are the most phases in applying business intelligence solutions for the different companies and vary from field and sector to another as shown in Figure 7. The planning and analzing phases is very useful for forcasting in the marketing researches. 


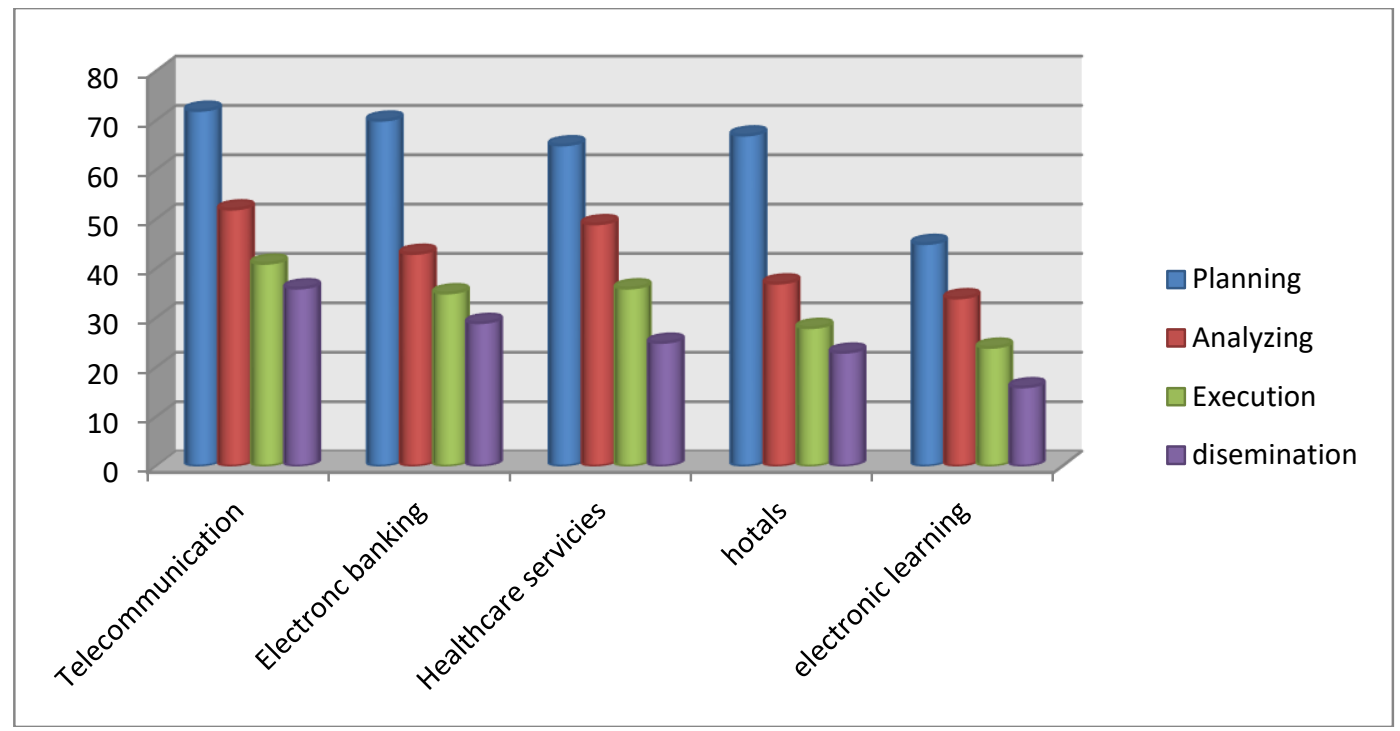

Figure 7. The perentages of framework's phase according to different sectors

By applying business intelligence solution framework on companies, we can gain the results:

- It is useful to applying business intelligence solution framework on different categories of sectors which promoting servicies and products like telecommunication companies, airlines, healthcare, electronic learning and electronic banking manufacturers, electronic commence businesses, retailers, financial services, bioinformatics and hotels.

- The business intelligence solution framework can assist in customer relationship management, market research, cutomers segmentation, product profitability, inventory and distribution analysis, statistical analysis, supply chain management, strategic management, Business Process Management, knowledge management etc.

- By implementing the phases of business intelligence solutions framework, it's pereferable to understand each phase. Also there are some phases is more applied like using business intelligence in planning and analyzing in order to forecasting for new insights and decisions.

- There is a need to quick and real time forcasting and analytical systems through the globalization market to reach to a new insights and gain opportunities and catch directives.

- Using business intelligence solutions can use in decision making to develop and predict in making strategic decisions.

\section{CONCLUSION}

Business intelligence solutions can improve businesses process modeling quality and present the right solution in the right time. The complexity of today's business environment requires companies to be agile and proactive in relation to decision-making processes [23].

According to the increasing of the data types and volumes from different resources in the organization, the business intelligence solutions have become necessary for any company in decision making in market researches. Also, using business intelligence solutions for Forecasting can have a good role in improving the efficiency of market researches, which is reflected positively on the planning accuracy in all parts of the organization. Finally, using business intelligence for forecasting in market researches proves its importance and usefulness in relation with ensuring the quality of economic activities and processes within organizations.

\section{FUTURE WORK}

The proposed business intelligence framework can apply in different market researches for services and products. Also the business intelligence solutions need to evaluate and test in order to estimate the impacts of the decisions in the markets researches and analyze through applying on complex business scenarios.

In the future works, its essential to measure main objectives of using intelligence solutions in market researches such as efficiency, effectiveness, and differentiation. 


\section{REFERENCES}

[1] S. Williams and N. Williams, "The Profit Impact of Business Intelligence, ” Morgan Kaufmann, 2010.

[2] C. Vercellis. "Business Intelligence: Data Mining and Optimization for Decision Making.", Wiley-Blackwell, 2009.

[3] SAP AG. "Data Warehousing (BW310)." SAP AG, 2007

[4] Kent, P., Viewpoint: Big data and big analytics means better business, from http://www.bbc.co.uk/news/business19969588, 2012.

[5] Liu Luhao, "Supply Chain Integration through Business Intelligence; Management and Service Science (MASS)," International Conference on Digital Object Identifier. Publication Year: 2010 , Page(s): 1 -4 IEEE Conferences.

[6] Zuluaga, Givanni Gomez, "Smart Decision Infrastructure: Architecture Discussion." Cybernetics \&Systems, vol. 42 no. 2, pp. 139-155, March 2011.

[7] B. Sajjad, A. Mir, A. Khawar, F. Bashir and A. Tariq, "An open source service oriented Mobile Business Intelligence Tool (MBIT)," 2009 International Conference on Information and Communication Technologies, Karachi, 2009, pp. 235-240.

[8] W. H. Inmon, “Building the Data Warehouse.” ISBN: 978-0764599446, John Wiley \& Sons, 2005.

[9] SAP AG, DataSource,

http://help.sap.com/saphelp_nw73/helpdata/en/4a/141277174f0452e10000000a421937/content.ht $\mathrm{m}$ ?frameset=/en/4a/373a435e291c67e10000000a42189c/frameset.htm, 2013.

[10] SAP AG, Persistent Staging Area, http://help.sap.com/saphelp_nw73/helpdata/en/7d/724d3caa70ea6fe10000000a114084/content.htm, 2013.

[11] SAP AG, “BI - Enterprise Reporting, Query \&Analysis (Part I) (BW305). ” SAP AG, 2007.

[12] J. He, C. Wu and J. Li, "Research on EDA based Right-Time Business Intelligence System," 2010 2nd IEEE International Conference on Information Management and Engineering, Chengdu, 2010, pp. 476-479.

[13] A. Palmer and B. Hartley, "The Business and Marketing Environment, 3rd ed.," London: McGraw-Hill, 1996.

[14] Guarda, Gaspar dos Santos et al. "Pervasive Business Intelligence: a Marketing Intelligence Framework Proposal." (2015).

[15] W. W. Eckerson, “Performance Dashboards: Measuring, Monitoring, and Managing Your Business, ” Wiley, 2010.

[16] J. Ranjan, "Business justification with business intelligence," VINE, vol. 38, no. 4, pp. 461-475, 2008.

[17] Yujun Bao et al, "Research of Business Intelligence Which Based Upon Web, ” E-Business and Information System Security. EBISS '09. International Conference on Digital Object Identifier. Page(s): 1 - 4 IEEE Conferences, 2009.

[18] Sharp, S., "Competitive Intelligence Advantage: How to Minimize Risk, Avoid Surprises, and Grow Your Business in a Changing World," Wiley, 2009.

[19] A. Habul and A. Pilav-Velic, "Business intelligence and customer relationship management," Proceedings of the ITI 2010, 32nd International Conference on Information Technology Interfaces, Cavtat, 2010, pp. 169-174.

[20] Rasoul, D. G., and Mohammad, H., A model of measuring the direct and impact of business intelligence on organizational agility with partial Mediatory role of Empowerment: Tehran construction Engineering Organization (TCEO) and EKTA organization industries.co.” Social and Behavioral Sciences, vol. 230, pp. 413-421, 2016.

[21] Rathore, S., Panwar, A., \& Soral, P., "Critical factors for successful implementation of business analytics: Exploratory findings from select cases.” International Journal of Business Analytics and Intelligence, vol. 2, no. 2, pp. 12-22, 2014.

[22] Robert Walters, Your guide to the 2018 business intellegence market, www.robertwalters.co.uk,2018.

[23] P. Bocij, A. Greasley, and S. Hickie, "Business information systems: Technology, development and management," Ft Press, 2009.

\section{BIOGRAPHY OF AUTHOR}

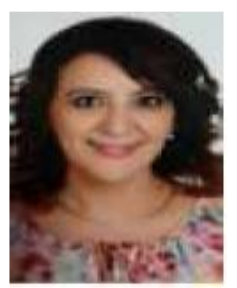

Christina Albert Rayed Assad

Associate Professor

Computer and Information System Department

Sadat Academy for Management Science, Cairo, Egypt 